\title{
A Heat Resistant and Flame-Retardant Polysulfonamide/Polypropylene Composite Nonwoven for High Performance Lithium Ion Battery Separator
}

\author{
Liping Yue, ${ }^{\text {a,b }}$ Jianjun Zhang, ${ }^{\text {b }}$ Zhihong Liu, ${ }^{\mathrm{b}}$ Qingshan Kong, ${ }^{\mathrm{b}}$ Xinhong Zhou, ${ }^{\mathrm{a}, \mathrm{z}}$ Quan Xu, \\ Jianhua Yao, ${ }^{\text {b }}$ and Guanglei Cui ${ }^{\text {b,z }}$
}

\author{
${ }^{a}$ College of Chemistry and Molecular Engineering, Qingdao University of Science and Technology, \\ Qingdao 266042, People's Republic of China \\ ${ }^{b}$ Qingdao Key Lab of Solar Energy Utilization and Energy Storage Technology, Qingdao Institute of Bioenergy and \\ Bioprocess Technology, Chinese Academy of Sciences, Qingdao 266101, People's Republic of China
}

\begin{abstract}
A heat resistant and flame-retardant polysulfonamide/polypropylene composite nonwoven has been developed and exploited as an advanced separator for high performance lithium ion battery via melt-blown spinning followed by a phase-inversion process. It was manifested that such composite nonwoven exhibited improved flame retardance, superior thermal resistance and better electrolyte wettability as compared to commercialized polypropylene separator. It was also demonstrated that the lithium cobalt oxide $\left(\mathrm{LiCoO}_{2}\right)$ /graphite cells employing the composite separator possessed better rate capability and superior cycling stability than those of polypropylene separator. Furthermore, this study verified the beneficial impact of polysulfonamide/polypropylene composite separator with respect to commercial polypropylene separator on cycle performance of lithium iron phosphate $\left(\mathrm{LiFePO}_{4}\right) / \mathrm{lithium}$ (Li) cells even at an elevated temperature of $120^{\circ} \mathrm{C}$. These fascinating results suggest that such composite nonwoven is promising separator for high performance lithium ion battery.

(C) 2014 The Electrochemical Society. [DOI: 10.1149/2.059406jes] All rights reserved.
\end{abstract}

Manuscript submitted November 14, 2013; revised manuscript received April 14, 2014. Published May 2, 2014.

Lithium ion battery (LIB) is considered to be the most promising technology for electric vehicles and energy storage systems due to its high-energy density, high-specific energy, low self-discharge rate, and long lifetime cycle. ${ }^{1-5}$ Among the components in lithium ion battery, the separator is a critical component for battery performance and also crucial for battery safety. The separator separates positive electrode and negative electrode while permitting the rapid diffusion of lithium ions through electrolyte. ${ }^{6,7}$ Microporous polyolefin-based separators, such as polyethylene and polypropylene membranes, have been commercially used as major separators for LIB because of satisfactory mechanical property, excellent chemical stability and good thermal shutdown properties. ${ }^{8-10}$ The thermal shutdown property of the microporous separators could cut off the thermal runaway at the shutdown temperature. ${ }^{6}$ However, the microporous polyolefin separators often suffered from severe thermal shrinkage above melting temperature when the elevated temperature kept a little long time, which could cause direct contact between cathode and anode and finally result in short circuit of lithium battery. ${ }^{11}$ Meanwhile, the microporous polyolefin separators have been proven to cause poor electrolyte wettability problems, which lead to an increase in cell resistance and would restrict the battery performance. ${ }^{12,13}$ Tremendous efforts have been made to improve the overall properties of commercial polyolefin separators. ${ }^{14-17}$ One strategy was to incorporate inorganic nanoparticles into microporous polyethylene membrane (PE) or polypropylene membrane (PP) and the other one was to coat high performance polymers onto commercial separator surface. As a matter of fact, ceramic nanoparticles coating suffered from insufficient adhesion to polymer matrix, which could lead to the particles detached from separators' surface and generate a non-uniform current density across the electrodes during cycling, causing accelerated capacity degradation and battery deterioration. ${ }^{10,14}$ For the polymer coating of commercial microporous PP separators could reduce the porosity and increase cell resistance. ${ }^{17}$

Nonwoven-based membranes are attractive materials to meet these demands, because they possess high porosity and can readily composite with other materials such as ceramic nanoparticle and high performance polymer. ${ }^{18,19}$ Polypropylene nonwovens are manufactured by melt-blown spinning technique. The technique possesses several advantages such as high output, low processing cost and can produce high porosity and lightweight nonwoven. Nevertheless, polypropylene nonwovens have not yet been served as the separator alone for

zE-mail: zxhhx2008@163.com; cuigl@qibebt.ac.cn lithium ion battery due to its large pore size, which may lead to severe self-discharge and internal short circuits of the battery. ${ }^{20}$ It is well known that phase inversion is a facile strategy to produce large scale porous polymeric membranes, which have been successfully used for fabrication of ultrafiltration and microfiltration membranes, as well as gas separation membranes. ${ }^{7,21}$ Polysulfonamide polymers are well defined by their heat resistance subjected to a high temperature, which can be tailored by using the polymer as a matrix of multiphase composites. ${ }^{22,23}$ Inspired by phase-inversion and thermal resistant polysulfonamide, we combined both advantage together and demonstrated a heat resistant and flame-retardant PSA/PP composite nonwoven (hereinafter, abbreviated as "PSAP separator") as a promising lithium ion battery separator via melt-blown spinning method followed by a phase-inversion process.

To the best of our knowledge, few studies have been carried out on PSAP separator for high performance lithium ion battery. The aim of the present paper is to highlight the effect of PSA reinforced polypropylene nonwoven in such cells. As compared to commercialized microporous polypropylene separator (MPP separator), PSAP separator displayed better electrolyte wettability, superior thermal resistance and better battery performance. It is also demonstrated that PSAP separator is a promising alternative for lithium ion battery.

\section{Experimental}

Materials.- Polypropylene material and phenoxy polyphosphazene was purchased from Shandong Botao Company. Polysulfonamide (PSA) was purchased from DuPont Company. N, Ndimethylacetamide (DMAc, 99.5\%) was supplied by Sinopharm Chemical Reagent Co., Ltd. Commercialied microporous polypropylene separator (MPP separator, Celgard 2400) was purchased from Celgard Company (USA) and used as comparative analysis. Lithium cobalt oxidate $\left(\mathrm{LiCoO}_{2}\right)$ was supplied by Citic GuoAn Power Technology Co., Ltd. Graphite powder was supplied by Sigma-Aldrich Co., Ltd. Lithium iron phosphate $\left(\mathrm{LiFePO}_{4}\right)$ was supplied by Tianjin STL Energy Technology Co., Ltd. $1 \mathrm{M}$ lithium hexafluorophosphate $\left(\mathrm{LiPF}_{6}\right)$ in ethylene carbonate $(\mathrm{EC}) /$ dimethyl carbonate $(\mathrm{DMC})(1 / 1$, V/V) was supplied by Guotai-huarong New Chemical Materials Co., Ltd. Lithium bis(oxalate) borate (LiBOB) was supplied by Suzhou Fotai New Materials Co., Ltd. Propylene carbonate (PC) was supplied by Shenzhen Capchem Technology Co., Ltd. 


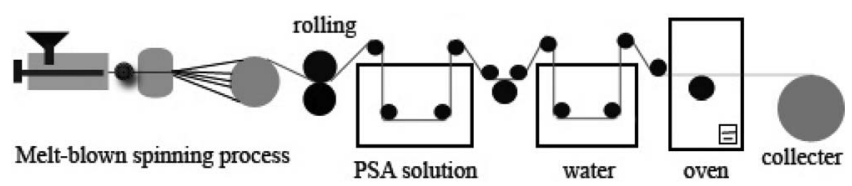

Scheme 1. Schematic illustration for the fabrication of PSAP separator.

the melt-blown spinning step, PP raw material and phenoxy polyphosphazene $(400 \mathrm{~g})$ were conveyed to screw extruder and heated at $200^{\circ} \mathrm{C}$ for $2 \mathrm{hrs}$ to form polymer melt, then the polymer melt was pulled into ultra-fine fibers from the spinneret holes at high pressure. The obtained melt-blown nonwoven was then rolled by hot calendering and obtained polypropylene nonwoven.

For the phase inversion step, PSA (600 g) was dissolved in $1 \mathrm{~L}$ DMAc with stirring to give the homogeneous solution. After that, polypropylene nonwoven was immersed into PSA solution and followed by immediately delivered to coagulation bath and kept for 15 min to generate PSAP composite nonwoven. The PSAP composite nonwoven was dried in an oven at $60^{\circ} \mathrm{C}$ for $1 \mathrm{~h}$ and then was collected for future evalution.

Characterization of the separators. - The morphology of the separators was observed by field emission scanning electron microscope (SEM, Hitachi S-4800). The air permeability was measured using the Gurley-type densometer (4110 N, Gurley), the Gurley value was defined as the time of $100 \mathrm{cc}$ air to pass through the separator. The porosity $(\mathrm{P})$ was defined as the ratio of void volume to apparent geometric volume. It was determined using n-butanol uptake method and then calculated using Eq. (1): $\mathrm{P}=\left[\left(\mathrm{W}_{\mathrm{f}}-\mathrm{W}_{\mathrm{o}}\right) / \rho \mathrm{V}\right] \times 100 \%$, where $\mathrm{W}_{\mathrm{f}}$ and $\mathrm{W}_{\mathrm{o}}$ are the weight of the wet and dry membranes, respectively; $\rho$ is the density of $n$-butanol; and V is the apparent volume of the membrane. The electrolyte uptake (EU), expressed as a percentage, was defined as the weight ratio of the electrolyte solution absorbed by the polymer membrane to the polymer. It was determined using liquid electrolyte $\left(1 \mathrm{M} \mathrm{LiPF}_{6}\right.$ in $\left.\mathrm{EC} / \mathrm{DMC}(1: 1, \mathrm{~V}: \mathrm{V})\right)$ and then calculated by following Eq. (2): $E U=\left[\left(\mathrm{W}-\mathrm{W}_{\mathrm{o}}\right) / \mathrm{W}_{\mathrm{o}}\right] \times 100 \%$, where $\mathrm{W}_{\mathrm{o}}$ and $\mathrm{W}$ indicate the weight of separator before and after liquid electrolyte absorption, respectively. For these measurements, each sample was immersed in the n-butanol or liquid electrolyte for $2 \mathrm{hrs}$. The weight of sample was measured after removing the excess amount of n-butanol or liquid electrolyte.

Thermal property and flame resistance measurements. - Separators were cut into squares $(2 \mathrm{~cm} \times 2 \mathrm{~cm})$ and dimensional changes were monitored after keeping the separators from $100^{\circ} \mathrm{C}$ to $150^{\circ} \mathrm{C}$ for $1 \mathrm{~h}$. Thermal shrinkage ratio (TSR) was calculated using the following Eq. (3): $\operatorname{TSR}(\%)=\left[\left(\mathrm{S}_{\mathrm{o}}-\mathrm{S}\right) / \mathrm{S}_{\mathrm{o}}\right] \times 100 \%$. Here, $\mathrm{S}_{\mathrm{o}}$ and $\mathrm{S}$ represent the area of the separator before and after thermal treatment at a series of temperature for $1 \mathrm{~h}$, respectively. Limiting oxygen index (LOI) measurement was undertaken using JF-3 type oxygen index tester (China). Heat release value was determined by automatic oxygen bomb calorimeter.

Electrochemical measurements. - The electrochemical stability of the separator was conducted by a linear sweep voltammetry (LSV) test. The separator was sandwiched between a stainless-steel working electrode and a lithium metal reference electrode at a scan rate of $1.0 \mathrm{mV} \mathrm{s}^{-1}$ from $2.5 \mathrm{~V}$ to $6.0 \mathrm{~V}$ vs. $\mathrm{Li}^{+} / \mathrm{Li}$ to check oxidative decomposition.

Ionic conductivity of separators was measured by preparing cells where liquid electrolyte impregnated separators were sandwiched between stainless steel blocking electrodes (diameter: $16.2 \mathrm{~mm}$ ). The ionic conductivity $(\sigma)$ is calculated by employing the formula: $\sigma=\mathrm{L} / \mathrm{AR}_{\mathrm{b}}$, where $\mathrm{L}$ is the thickness of the separator sample and $\mathrm{A}$ is the contact area between the separator and the electrode. The ionic conductivity was determined from bulk resistances $\left(\mathrm{R}_{\mathrm{b}}\right)$, which were measured by $\mathrm{AC}$ complex impedance analyzes using an impedance analyzer in combination with Zahner Zennium Electrochemical Workstation over a frequency range from $1.0 \mathrm{~Hz}$ to $10^{6} \mathrm{~Hz}$ with $10 \mathrm{mV}$ of AC amplitude.

Battery properties. - Battery tests such as rate capability and cycle life were carried out using a LAND battery testing system in the voltage range of $2.75 \mathrm{~V}-4.20 \mathrm{~V}$ at room temperature using 2032 coin type cell consisting of $\mathrm{LiCoO}_{2}$ electrode as a cathode, graphite electrode as an anode and $1 \mathrm{M} \mathrm{LiPF}_{6}-\mathrm{EC} / \mathrm{DMC}$ (1:1 in volume) as an electrolyte. The charge/discharge performance was evaluated under a constant charge/discharge current and constant voltage charge along with the discharge densities were varied form $0.2 \mathrm{C}\left(26 \mathrm{~mA} \mathrm{~g}^{-1}\right)$ to 8.0 $\mathrm{C}\left(1040 \mathrm{~mA} \mathrm{~g}^{-1}\right)$ for rate capability and $0.5 \mathrm{C}\left(65 \mathrm{~mA} \mathrm{~g}^{-1}\right)$ for cycle test.

Cycle performance at elevated temperature were carried out using a LAND battery testing system in the voltage range of $2.5 \mathrm{~V}-4.0 \mathrm{~V}$ at $120^{\circ} \mathrm{C}$ using 2032 coin type cell consisting of $\mathrm{LiFePO}_{4}$ electrode as a cathode, lithium metal as an anode and $0.5 \mathrm{M} \mathrm{LiBOB}-\mathrm{PC}$ as an electrolyte. The charge/discharge performance was evaluated under a constant charge/discharge current and constant voltage charge along with the discharge densities were varied form $0.5 \mathrm{C}\left(65 \mathrm{~mA} \mathrm{~g}^{-1}\right)$.

\section{Results and Discussion}

Membrane characteristics of polypropylene nonwoven and PSAP separator-The morphological characterization of polypropylene nonwoven and PSAP separator were elucidated in Figure 1. It was clearly observed in Figure 1a that the average diameter size of polypropylene fibers was $2 \pm 0.1 \mu \mathrm{m}$ and the polypropylene nonwoven exhibited excessively large-sized pores $(>3 \mu \mathrm{m})$, which may lead to internal short circuits and a decrease in open voltage of the battery. It was demonstrated in Figure $1 \mathrm{~b}-1 \mathrm{c}$ that the pores of PSAP separator were homogeneously distributed and the diameter was about $1 \mu \mathrm{m}$. As shown in Figure 1d, the average thickness of PSAP separator was $50 \mu \mathrm{m}$ and it possessed tortuously labyrinth-like porous structure. The well interconnected microporous structure and intrinsically lyophilic nature of PSAP separator was expected to prevent the growth of lithium dendrites and absorb more electrolyte, resulting in high ionic conductivity. ${ }^{24-26}$

Table I listed the thickness, porosity, air permeability and electrolyte uptake of MPP separator, polypropylene nonwoven and PSAP separator, respectively. Gurley value of polypropylene nonwoven was $0.5 \mathrm{~s}$ due to its larger pore sizes. However, Gurley value of PSAP separator was $26 \mathrm{~s}$, which was much lower than that of MPP separator
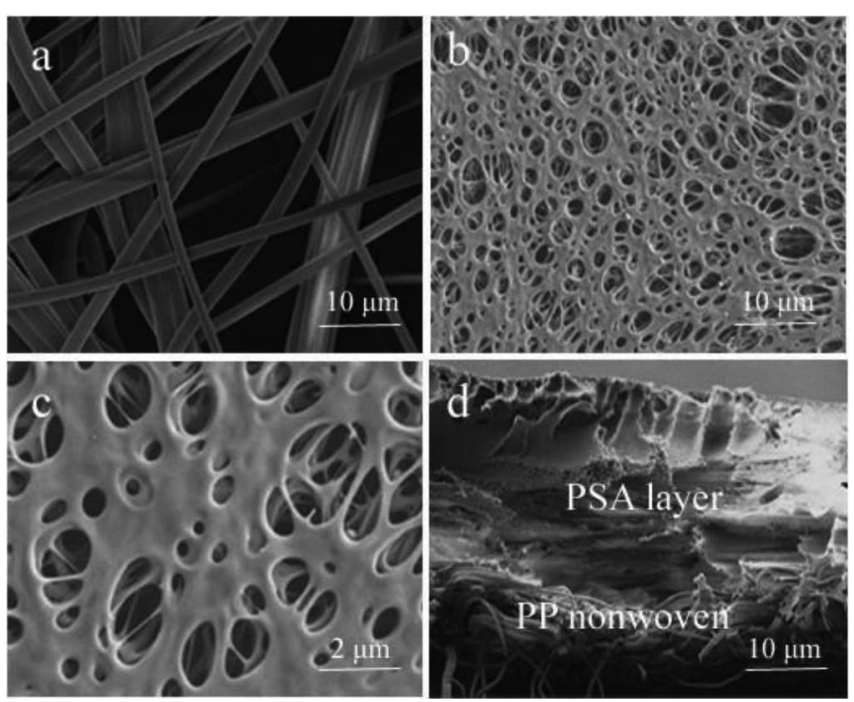

Figure 1. Typical SEM images of (a) polypropylene nonwoven; (b-c) PSAP separator with different magnification and (d) cross-section of PSAP separator. 
Table I. Brief parameters of commercial MPP separator, polypropylene nonwoven and PSAP separator.

\begin{tabular}{cccccc} 
Sample & Thickness $(\mu \mathrm{m})$ & Porosity $(\%)$ & Gurley value $(\mathrm{s} / 100 \mathrm{cc})$ & Electrolyte Uptake $(\%)$ & LOI $(\%)$ \\
\hline MPP separator & 25 & 35 & 492 & 127 & 18 \\
Polypropylene nonwoven & 30 & 90 & 0.5 & 250 & 200
\end{tabular}

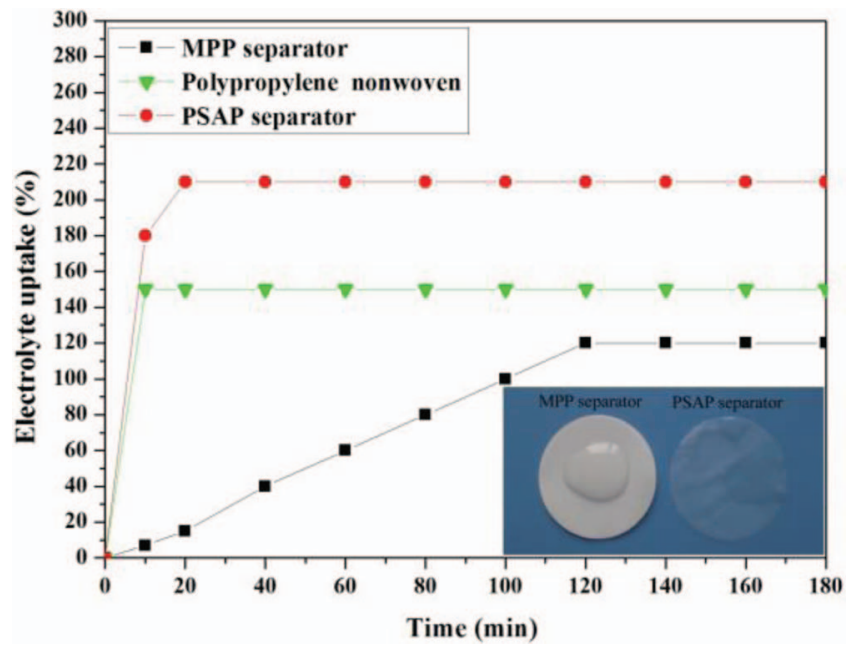

Figure 2. Electrolyte uptake vs. time curves of MPP separator, polypropylene nonwoven and PSAP separator. The inset is the photographs showing liquid electrolyte $\left(1 \mathrm{M} \mathrm{LiPF}_{6}\right.$ in EC/DMC $(1: 1, \mathrm{~V}: \mathrm{V})$ wetting behavior of MPP separator and PSAP separator.

(492 s). It is well recognized that highly microporous structure of separator generate lower Gurley value. The improvement in the microporous structure of PSAP separator was consistent with its porosity. Notably, the porosity of PSAP separator $(65 \%)$ was fairly higher than that of MPP separator (35\%) and lower than that of polypropylene nonwoven $(90 \%)$. It was deduced that although PSA coating reduced the porosity of polypropylene nonwoven, PSAP separator still possessed considerable porosity for holding sufficient liquid electrolyte in facilitating free ionic transportation and improving ionic conductivity. ${ }^{6,27-30}$

The electrolyte uptake of separators was crucial for cycle performance of lithium ion battery. Figure 2 displayed electrolyte uptake curves of MPP separator, polypropylene nonwoven and PSAP separator at varied time. And the inset vividly showed that the wettability of MPP separator was poor due to its intrinsically hydrophobic nature and low surface energy. ${ }^{31}$ In contrast, PSAP separator was easily soaked and the electrolyte droplets rapidly spread over a wide area of the separator. Obviously, the electrolyte uptake of PSAP separator took within $20 \mathrm{~min}$, while it took more than $2 \mathrm{~h}$ to reach its maximum value for MPP separator. The comparatively higher uptakes of liquid electrolyte implied that better affinity exists between PSAP separator and the liquid electrolyte. The enhanced electrolyte wettability and uptake of PSAP separator may be ascribed to the well interconnected microporous structure and the intrinsically lyophilic nature of polysulfonamide material. ${ }^{32}$ Both the highly developed porous structure and good electrolyte wettability were expected to allow fast ion transport in PSAP separator, which thus contributed to better rate capability of the cells. ${ }^{33-35}$

Thermal resistance and flame retardancy.- Thermal shrinkage of the separators was another significant factor pertaining to safety characteristics of the lithium ion battery. ${ }^{36-38}$ Hot oven test was conducted for MPP separator, polypropylene nonwoven and PSAP separator for $1 \mathrm{~h}$ storage. As shown in Figure 3a, PSAP separator exhibited negligible thermal shrinkage than the MPP separator over a wider range of temperatures from $100^{\circ} \mathrm{C}$ to $150^{\circ} \mathrm{C}$, which verified that the introduction of PSA coating is effective in improving the thermal dimentional stability of separators. ${ }^{20}$ It could be seen in Figure $3 b$ that PSAP separator exhibited negligible dimension change, while MPP separator shrank by $50 \%$ at the uniaxially stretched direction. This superior thermal tolerance could prevent internal electrical short circuit at elevated temperature during cell cycling. Hence, PSAP separator was expected to be a highly safe separator for lithium ion battery with requested thermal safety.

The flame retarding capability of the separator was a critical factor for improving the safety of lithium ion battery and has been very rarely mentioned because most polyolefin-based separators are combustible. ${ }^{39}$ Combustion test of MPP separator and PSAP separator in air was shown in Figure 4. When MPP separator was set on fire, the separator shrank immediately and caught fire within short time $(<3 \mathrm{~s})$ (Figure $4 \mathrm{a}, 4 \mathrm{c})$. In contrast, PSAP separator showed excellent flame retarding ability. It did not be ignited even when set on fire (Figure 4b, 4d). Limiting oxygen index (LOI) is a parameter for evaluating flame retardancy and flammability of polymeric materials. The higher the value of LOI is, the better the flame retardancy is. The LOI results for the samples were depicted in Table I. It can be seen
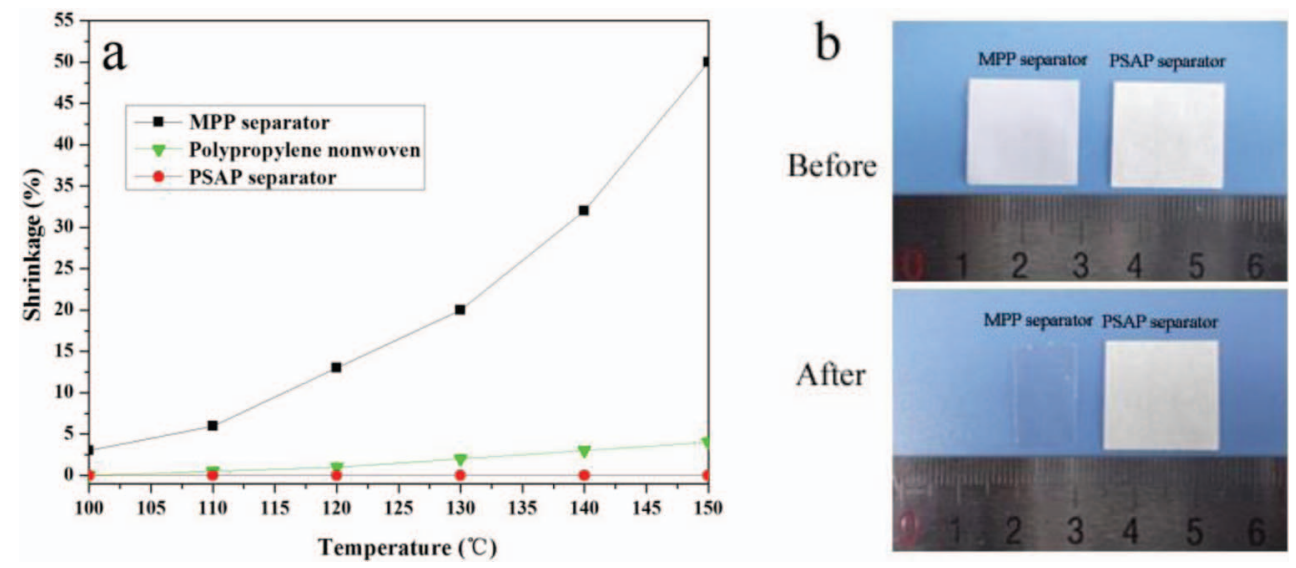

Figure 3. (a) The thermal shrinkage of MPP separator, polypropylene nonwoven and PSAP separator over a wider range of temperatures from $100^{\circ} \mathrm{C}$ to $150^{\circ} \mathrm{C}$; (b) The photographs of MPP separator and PSAP separator before and after thermal treatment at $150^{\circ} \mathrm{C}$ for $1 \mathrm{~h}$. 


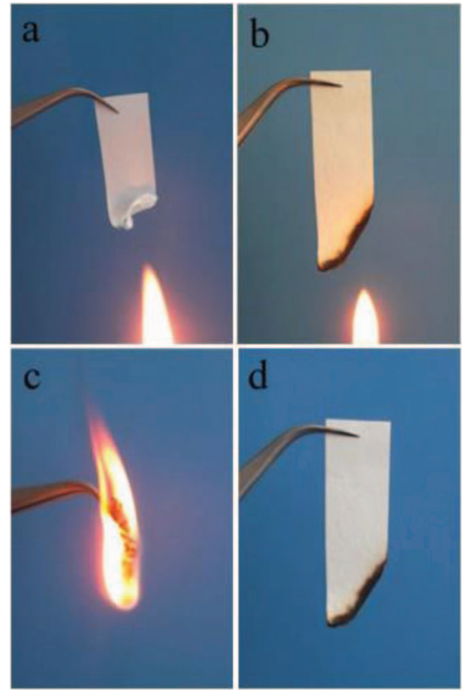

Figure 4. Combustion test of (a, c) MPP separator and (b, d) PSAP separator.

that PSAP separator presented higher LOI values $(25 \%)$ than that of MPP separator (18\%). The inflame retarding property of PSAP separator was superior to that of MPP separator. The main reason was that compositing PSA improved heat resistance and phenoxy polyphosphazene enhanced flame retardancy of polypropylene nonwoven. This superior inflame retarding property endow better safety performance for PSAP separator compared to MPP separator.

Electrochemical characterization.- It is important to investigate the electrochemical stability of separator within the operation voltage of the battery system for practical battery applications. It was observed in Figure 5 that electrolyte soaked with MPP separator decomposed at about $4.8 \mathrm{~V} \mathrm{vs.} \mathrm{Li}^{+} / \mathrm{Li}$ which agreed well with the literature reported. ${ }^{40}$ While there are no obvious decomposition of any components in the electrolyte soaked with PSAP separator below $5.0 \mathrm{~V}$ vs. $\mathrm{Li}^{+} / \mathrm{Li}$. The high electrochemical stability would be ascribed to intrinsic high electrochemical stability of PSA material and superior interfacial compatibility between the carbonate electrolyte and separator. ${ }^{41}$ These results indicate that PSAP separator is very promising for applications in lithium ion battery.

Arrhenius plots of ionic conductivity of liquid electrolyte-soaked MPP separator and PSAP separator as a function of temperature was

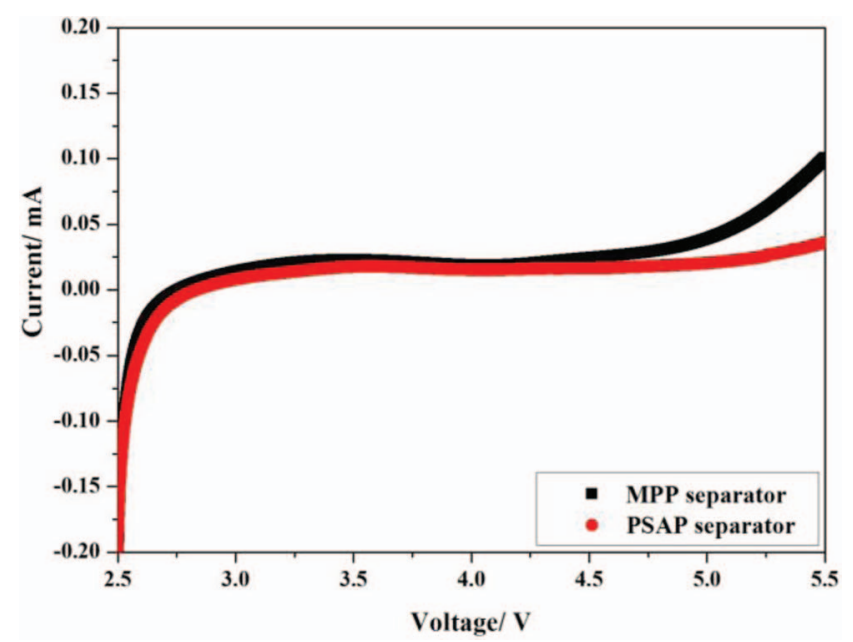

Figure 5. Linear sweep voltammograms for MPP separator and PSAP separator.

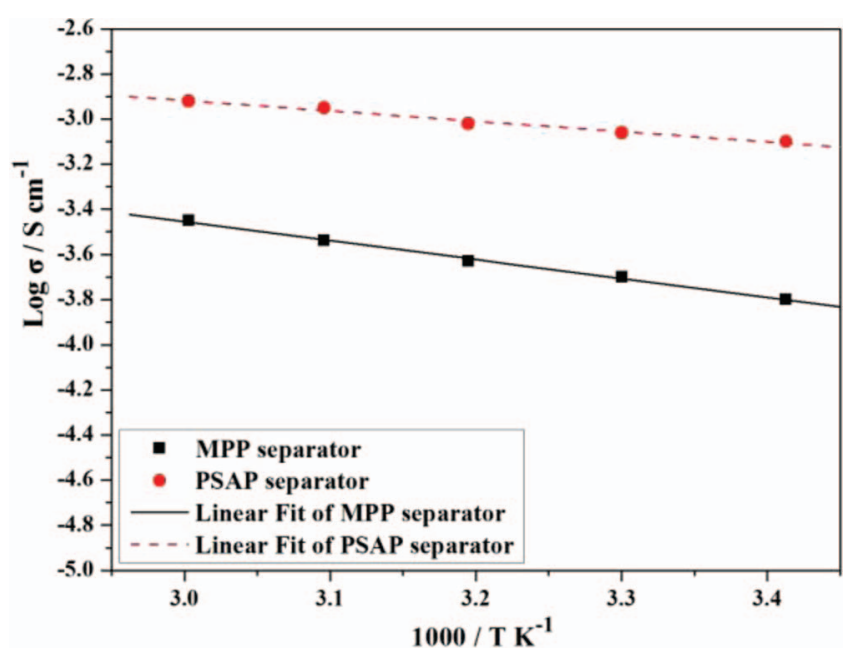

Figure 6. Arrhenius plots of ionic conductivity of liquid electrolyte-soaked MPP separator and PSAP separator.

depicted in Figure 6. It could be observed that ionic conductivity increases with increasing temperature. At $20^{\circ} \mathrm{C}$, the obtained ionic conductivity was $2 \times 10^{-4}$ and $8 \times 10^{-4} \mathrm{~S} \mathrm{~cm}^{-1}$ for MPP separator and PSAP separator, respectively. At $60^{\circ} \mathrm{C}$, the obtained ionic conductivity was $4 \times 10^{-4}$ and $1.2 \times 10^{-3} \mathrm{~S} \mathrm{~cm}^{-1}$ for MPP separator and PSAP separator, respectively. Considering the considerable porosity, ionic conductivity of liquid electrolyte-soaked PSAP separator was much higher than that of MPP separator mainly due to its interconnected porous structure and better electrolyte uptake. ${ }^{42,43}$ The linear plots suggested that the conductive behavior was basically agreed well with the Arrhenius equation over the temperature range of $20^{\circ} \mathrm{C}$ to $60^{\circ} \mathrm{C}^{44}$ Thus, the activation energy $\left(\mathrm{E}_{\mathrm{a}}\right)$ could be calculated from the slope of fitted straight line according to the Arrhenius equation $\sigma=A \exp \left(-E_{a} / R T\right)$, where $\sigma$ was conductivity of membrane, A was the pre-exponential index, $\mathrm{E}_{\mathrm{a}}$ was the activation energy, $\mathrm{R}$ was gas constant $\left(8.314 \mathrm{~J} \mathrm{~K}^{-1} \mathrm{~mol}^{-1}\right)$, and $\mathrm{T}$ was temperature $(\mathrm{K})$. The $\mathrm{E}_{\mathrm{a}}$ for MPP separator and PSAP separator were $15.83 \mathrm{~kJ} \mathrm{~mol}^{-1}$ and $8.84 \mathrm{~kJ} \mathrm{~mol}^{-1}$, respectively. Lower activation energy means faster ion diffusion, which favors enhanced ionic conductivity.

Rate capability and cycle performance of the $\mathrm{LiCoO}_{2} /$ graphite cells. - A key factor in determining the practical applications of PSAP separator is its endurable high-rate charge and discharge capability in lithium ion battery. Figure 7 depicted clearly that the rate

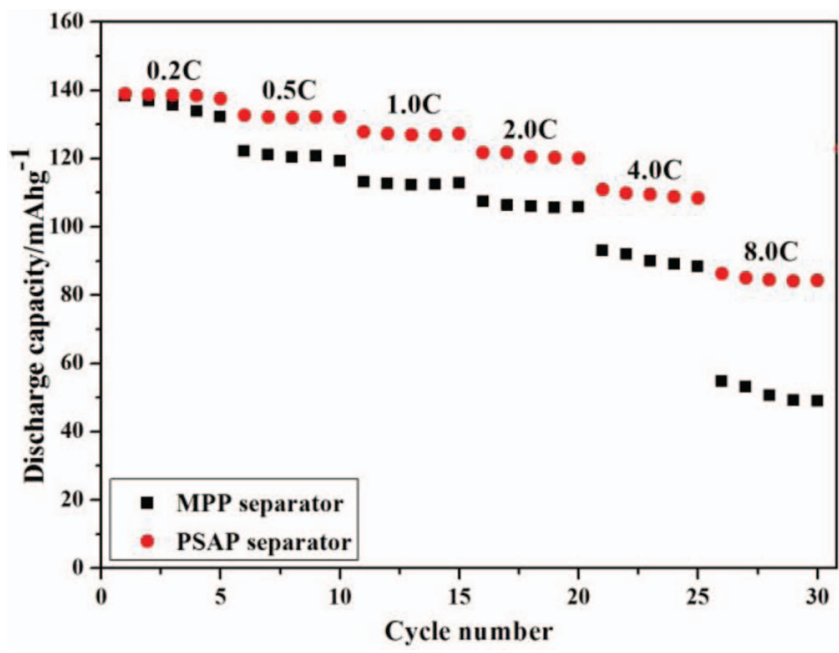

Figure 7. Rate capability of $\mathrm{LiCoO}_{2}$ /graphite cells with MPP separator and PSAP separator. 

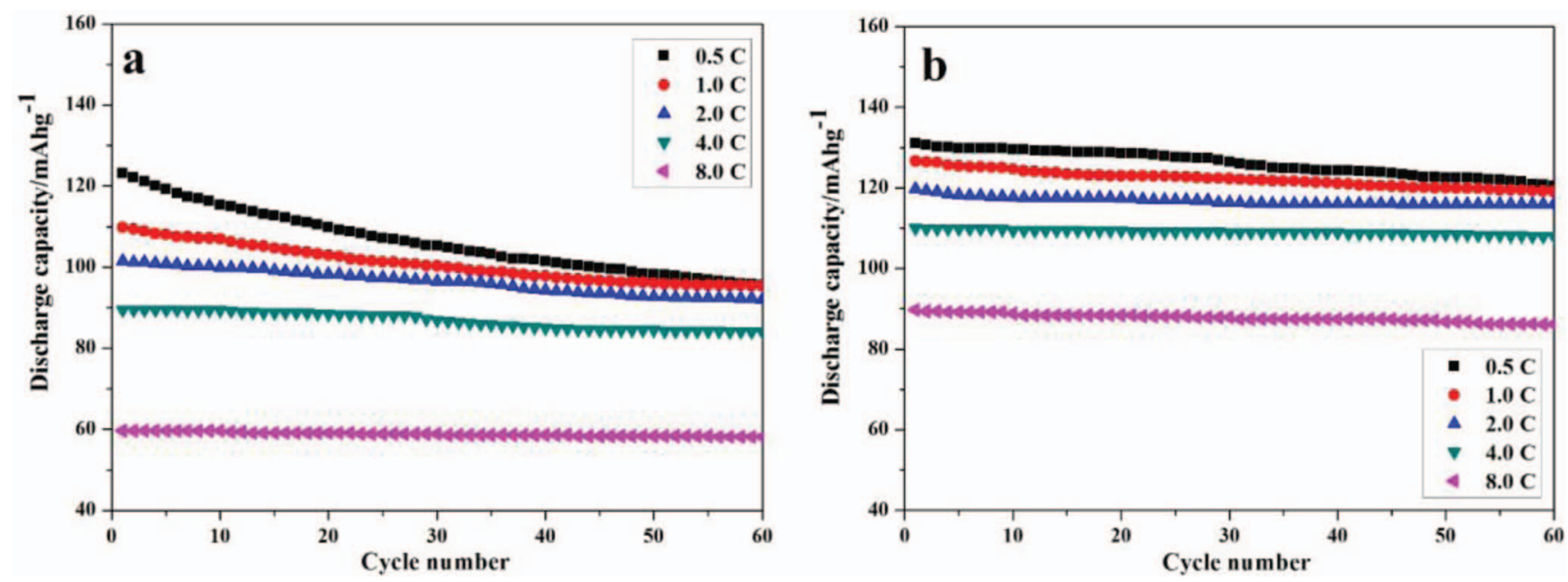

Figure 8. Typical cycle performance obtained at various rates from $0.5 \mathrm{C}$ to $8.0 \mathrm{C}$ for $\mathrm{LiCoO}_{2} /$ graphite cells employing (a) MPP separator and (b) PSAP separator.

capabilities of the $\mathrm{LiCoO}_{2}$ /graphite cells employing the MPP separator and PSAP separator. The discharging capacities of the MPP separator cells dropped drastically as discharging current densities increased from $0.2 \mathrm{C}\left(138 \mathrm{mAh} \mathrm{g}^{-1}\right)$ to $8 \mathrm{C}\left(50 \mathrm{mAh} \mathrm{g}^{-1}, 36.2 \%\right.$ of the discharging capacity at $0.2 \mathrm{C}$ ). By contrast, PSAP separator based cells exhibited much better capacity retention at varied rate. It was demonstrated that the cells assembled with PSAP separator showed higher discharge capabilities than that of MPP separator. This better rate performance is an indicator of a low resistance, which can be contributed to better ionic transport capability. ${ }^{26,45}$

Cycle life was also an important parameter for evaluating lithium ion battery. The capacity retention ratio as a function of cycle number at various rates from $0.5 \mathrm{C}$ to $8.0 \mathrm{C}$ for $\mathrm{LiCoO}_{2} /$ graphite cells using MPP separator and PSAP separator was shown in Figure 8. The cell with PSAP separator at $0.5 \mathrm{C}$ gave an initial discharge capacity of $133.1 \mathrm{mAh} \mathrm{g}^{-1}$ and retains $121 \mathrm{mAh} \mathrm{g}^{-1}$ after 60 cycles indicative of a better capacity retention ratio of around $90 \%$, while that of MPP separator retained $80 \%$ of its initial capacity. Futhermore, cycle performance of $\mathrm{LiCoO}_{2}$ /graphite cells at different rates from $1 \mathrm{C}$ and $8 \mathrm{C}$ was also measured. It was clearly noted that the cell with PSAP separator displayed much higher discharge capacity and more excellent cycle performance than MPP separator at various rates. The superior cycle performance of PSAP separator would be attributed to excellent liquid electrolyte retention and outstanding electrochemically interfacial stability. ${ }^{46,47}$

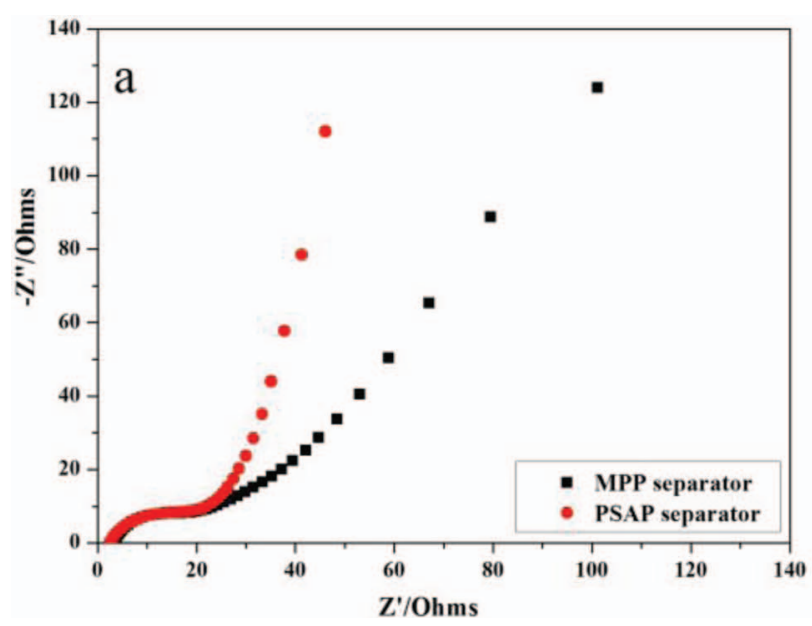

To investigate the variation of cell impedances during cycle performance test, AC impedance measurement was carried out for $\mathrm{LiCoO}_{2}$ /graphite cells assembled with MPP separator and PSAP separator after the first cycle and after the 100 cycles test. It is well known that the semicircle corresponds to the charge-transfer resistance due to lithium ion migration at the electrode/electrolyte interface. ${ }^{17}$ The straight slopping line corresponds to the diffusion resistances of lithium ion.

It was observed in Figure 9a that the charge-transfer resistance of PSAP separator after first cycle was $20 \Omega$, which slightly lower to that of MPP separator $(21 \Omega)$. However, obvious differences of the charge transfer regime after 100 cycles were observed in Figure $9 \mathrm{~b}$. The kinetic property was further investigated by modeling $\mathrm{AC}$ impedance spectra based on the modified equivalent circuit (Figure 9b). The fitting values from this equivalent circuit are presented in Table II. It was clearly shown that $\mathrm{R}_{\mathrm{ct}}$ of the PSAP separator after 100 cycles $35 \Omega$, whereas that of the MPP separator displayed 46 $\Omega$. The difference of charge-transfer resistance between MPP separator and PSAP separator was ascribed to a good compatibility between PSAP separator and liquid electrolyte. ${ }^{48}$

Cycling stability of $\mathrm{LiFePO}_{4} / \mathrm{Li}$ cells at elevated temperature.In the following study, cycle performance of lithium iron phosphate $\left.(\mathrm{LiFePO})_{4}\right) / \mathrm{Li}$ metal cells using MPP separator and PSAP separator are evaluated under $0.5 \mathrm{C}$ at an elevated temperature of $120^{\circ} \mathrm{C}$. As

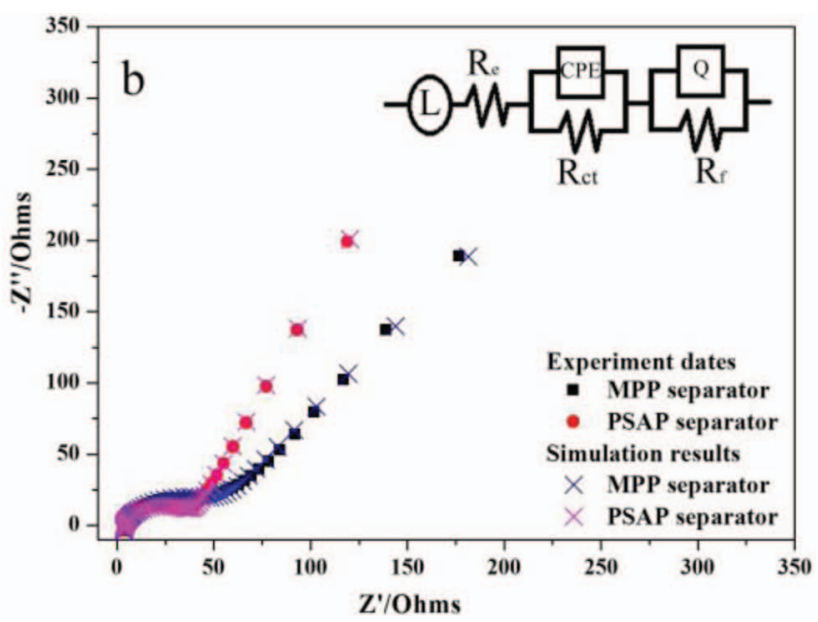

Figure 9. Nyquist plots for $\mathrm{LiCoO}_{2} /$ graphite cells using MPP separator and PSAP separator measured (a) after the first cycle and (b) after the 100 cycles test and the corresponding simulation results. Inset of $b$ is the equivalent circuit used. 


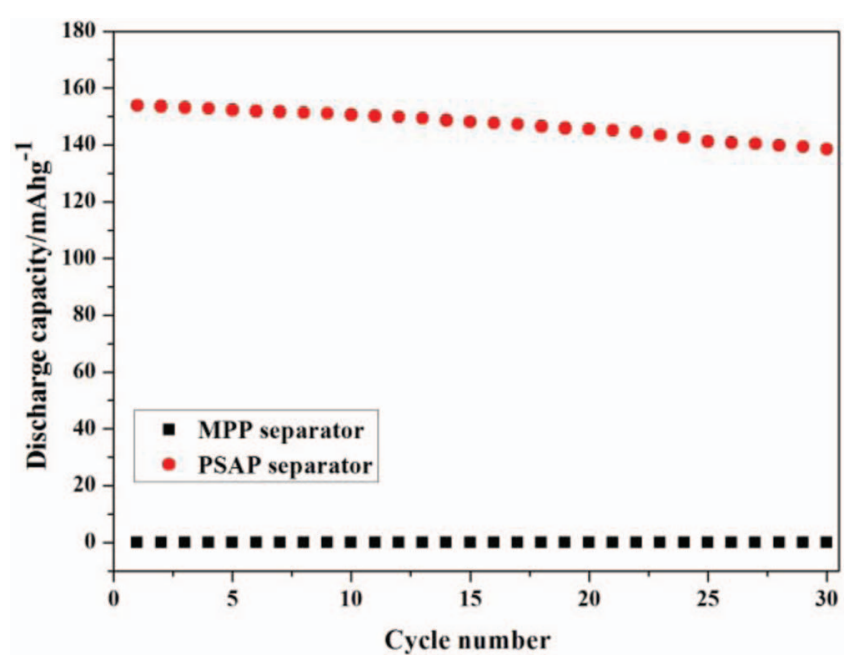

Figure 10. Cycling stability of $\mathrm{LiFePO}_{4} / \mathrm{Li}$ cells using MPP separator and PSAP separator at $120^{\circ} \mathrm{C}$.

Table II. Kinetic Parameters of the $\mathrm{LiCoO}_{2}$ /graphite cells using MPP separator and PSAP separator after the 100 cycles test.

\begin{tabular}{cccc} 
Sample & $\mathrm{R}_{\mathrm{e}}(\Omega)$ & $\mathrm{R}_{\mathrm{ct}}(\Omega)$ & $\mathrm{CPE}(\mathrm{F})$ \\
\hline MPP separator & 3.3 & 46 & $1.9 \times 10^{-5}$ \\
PSAP separator & 3.3 & 35 & $1.7 \times 10^{-5}$
\end{tabular}

shown in Figure 10, the discharge capacity retention after 30 cycles was found to be $90 \%$ for PSAP separator. In contrast, the cell using MPP separator could not charge and discharge at $120^{\circ} \mathrm{C}$. This could be explained that better thermal dimensional stability of PSAP separator maintained the unusual cycle performance of lithium ion battery at the elevated temperature, promising a possible long-term service life for high power lithium ion battery. ${ }^{49}$

\section{Conclusions}

We have developed a heat resistant and flame-retardant polysulfonamide/polypropylene composite nonwoven separator for potential application in high power lithium ion battery. Exploitation of a thermally stable PSA coating polypropylene nonwoven substrate enabled significant alleviation in the thermal shrinkage and remarkably improved resistance against thermal shrinkage at elevated temperatures. It was noted that such composite nonwoven separator possessed appropriate pore structure, superior electrochemical stability and high ionic conductivity. In comparison to MPP separator, such composite separator based $\mathrm{LiCoO}_{2} /$ graphite cell displayed enhanced rate capabilities and better cycle stability. In addition, $\mathrm{LiFePO}_{4} / \mathrm{Li}$ cell using this composite separator exhibited stable charge-discharge capability and satisfactory cycle performance even at an elevated temperature of $120^{\circ} \mathrm{C}$. All characteristics endow polysulfonamide/polypropylene composite nonwoven a promising separator for high performance lithium ion battery.

\section{Acknowledgment}

This work was financially supported by the National Program on Key Basic Research Project of China (973 Program) (No. MOST2011CB935700), the Instrument Developing Project of the Chinese Academy of Sciences (No. YZ201137), the National High Technology Research and Development Program of China (863 Program No.2013AA050905) and Natural Science Foundation of China (No. 21344003).

\section{List of Symbols}

PSA:

$\mathrm{LiCoO}_{2}$ :

polysulfonamide

lithium cobalt oxide

$\mathrm{LiFePO}_{4}$ :

LIB:

DMAc:

lithium iron phosphate

lithium ion battery

$\mathrm{LiPF}_{6}$ :

$\mathrm{N}, \mathrm{N}$-dimethylacetamide

EC: lithium hexafluorophosphate

PC: ethylene carbonate propylene carbonate

DMC: dimethyl carbonate

LiBOB: lithium bis(oxalate) borate

\section{References}

1. P. Arora and Z. M. Zhang, Chem. Rev., 104, 4419 (2004).

2. H. Li, Z. Wang, L. Chen, and X. Huang, Adv. Mater, 21, 4593 (2009).

3. J. M. Tarascon, Philos Trans. R. Soc. A-Math. Phys. Eng. Sci., 368, 3227 (2010).

4. B. Scrosati and J. Garche, J. Power Sources, 195, 2419 (2010).

5. P. G. Balakrishnan, R. Ramesh, and T. Prem Kumar, J. Power Sources, 155, 401 (2006).

6. X. S. Huang, J. Solid State Electrochem, 15, 649 (2011)

7. S. S. Zhang, J. Power Sources, 164, 351 (2007)

8. X. Huang and J. Hitt, J. Membr. Sci., 425-426, 163 (2013).

9. J. Ding, Y. Kong, P. Li, and J. Yang, J. Electrochem. Soc., 159, 1474 (2012).

10. J. Song, M. H. Ryou, B. Son, J. N. Lee, D. J. Lee, Y. M. Lee, J. W. Choi, and J. K. Park, Electrochim. Acta, 85, 524 (2012)

11. J. H. Cho, J. H. Park, J. H. Kim, and S. Y. Lee, J. Mater. Chem., 21, 8192 (2011).

12. D. Fu, B. Luan, S. Argue, M. N. Bureau, and I. J. Davidson, J. Power Sources, 206, 325 (2012).

13. J. Saunier, F. Alloin, J. Y. Sanchez, and G. Caillon, J. Power Sources, 119-121, 454 (2003).

14. J. Fang, A. Kelarakis, Y. W. Lin, C. Y. Kang, M. H. Yang, C. L. Cheng, Y. Wang, E. P. Giannelis, and L. D. Tsai, Phys. Chem. Chem. Phys., 13, 14457 (2011).

15. M. Kim and J. H. Park, J. Power Sources, 212, 22 (2012).

16. J. H. Cho, J. H. Park, J. H. Kim, and S. Y. Lee, J. Mater. Chem., 21, 8192 (2011).

17. M. H. Ryou, Y. M. Lee, J. K. Park, and J. W. Choi, Adv. Mater, 23, 3066 (2011)

18. E. S. Choi and S. Y. Lee, J. Mater. Chem., 21, 14747 (2011).

19. M. Chelmecki, W. H. Meyer, and G. Wegner, J. Appl. Polym. Sci., 105, 25 (2007).

20. Y. M. Lee, J. W. Kim, N. S. Choi, J. A. Lee, W. H. Seol, and J. K. Park, J. Power Sources, 139, 235 (2005).

21. T. H. Cho, T. Sakai, S. Tanase, K. Kimura, Y. Kondo, T. Tarao, and M. Tanaka, Electrochem. Solid-State Lett., 10, A159 (2007).

22. S. Wang, A. Ling, L. Wu, Y. Gao, S. Liu, Z. Wang, L. Sheng, and D. Kang, Desalination, 62, 221 (1987)

23. B. J. Xin, Z. M. Chen, X. J. Wu, and X. F. Wang, J. Ind. Text., 42, 434 (2013).

24. J. Ding, Y. Kong, and J. Yang, J. Electrochem. Soc., 159, 1198 (2012).

25. N. S. Choi, Y. M. Lee, J. H. Park, and J. K. Park, J. Power Sources, 119-121, 610 (2003).

26. J. H. Cho, J. H. Park, J. H. Kim, and S. Y. Lee, J. Mater. Chem., 21, 8192 (2011).

27. J. Zhang, Z. Liu, Q. Kong, C. Zhang, S. Pang, L. Yue, X. Wang, J. Yao, and G. Cui, ACS Appl. Mater. Interfaces, 5, 128 (2013).

28. J. Zhang, L. Yue, Q. Kong, Z. Liu, X. Zhou, C. Zhang, S. Pang, X. Wang, J. Yao, and G. Cui, J. Electrochem. Soc., 160, 769 (2013).

29. T. H. Cho, M. Tanaka, H. Onishi, Y. Kondo, T. Nakamura, H. Yamazaki, S. Tanase, and T. Sakai, J. Power Sources, 181, 155 (2008).

30. G. Venugopal, J. Moore, J. Howard, and S. Pendalwar, J. Power Sources, 77, 34 (1999).

31. X. J. Feng and L. Jiang, Adv. Mater, 18, 3063 (2006).

32. M. Rao, X. Geng, Y. Liao, S. Hu, and W. Li, J. Membrane Sci., 399-400, 37 (2012).

33. Y. J. Kim, C. H. Ahn, M. B. Lee, and M. S. Choi, Mater. Chem. Phys., 127, 137 (2011).

34. Y. Wang, H. Y. Zhan, J. Hu, Y. Liang, and S. S. Zeng, J. Power Sources, 189, 616 (2009).

35. S. J. Chun, E. S. Choi, E. H. Lee, J. H. Kim, S. Y. Lee, and S. Y. Lee, J. Mater. Chem., 22, 16618 (2012).

36. K. J. Kim, J. H. Kim, M. S. Park, H. K. Kwon, H. Kim, and Y. J. Kim, J. Power Sources, 198, 298 (2012)

37. X. Jia, G. Li, Y. Yu, G. Sui, H. Liu, Y. Li, P. Li, and X. Yang, J. Appl. Polym. Sci., 113, 283 (2009)

38. H. S. Jeong and S. Y. Lee, J. Power Sources, 196, 6716 (2011).

39. Z. Liu, W. Jiang, Q. Kong, C. Zhang, P. Han, X. Wang, J. Yao, and G. Cui, Macromol. Mater. Eng., 298, 806 (2013).

40. K. Xu, Chem. Rev., 104, 4303 (2004).

41. H. S. Jeong, J. H. Kim, and S. Y. Lee, J. Mater. Chem., 20, 9180 (2010).

42. F. Croce, M. L. Focarete, J. Hassoun, I. Meschini, and B. Scrosati, Energ. Environ. Sci., 4, 921 (2011).

43. L. C. Zhang, X. Sun, Z. Hu, C. C. Yuan, and C. H. Chen, J. Power Sources, 204, 149 (2012).

44. Y. X. Jiang, Z. F. Chen, Q. C. Zhuang, J. M. Xu, Q. F. Dong, L. Huang, and S. G. Sun, J. Power Sources, 160, 1320 (2006).

45. L. Jabbour, M. Destro, C. Gerbaldi, D. Chaussy, N. Penazzi, and D. Beneventi, J. Mater. Chem., 22, 3227 (2012). 
46. W. Jiang, Z. Liu, Q. Kong, J. Yao, C. Zhang, P. Han, and G. Cui, Solid State Ionics, 232, 44 (2013).

47. X. Zhou, L. Yue, J. Zhang, Q. Kong, Z. Liu, J. Yao, and G. Cui, J. Electrochem. Soc., 160, A1341 (2013).
48. K. Zhang, P. Han, L. Gu, L. Zhang, Z. Liu, Q. Kong, C. Zhang, S. Dong, Z. Zhang, J. Yao, H. Xu, G. Cui, and L. Chen, ACS Appl. Mater. Interfaces, 4, 658 (2012).

49. J. Zhang, Q. Kong, Z. Liu, S. Pang, L. Yue, J. Yao, X. Wang, and G. Cui, Solid State Ionics, 245-246, 49 (2013). 